\title{
Ponerse a cantar. Modos de autorrepresentación del poeta cantor en $E I$ gaucho Martín Fierro y en El guacho Martín Fierro.
}

\section{Resumen}

En el presente artículo se busca relevar y analizar de forma comparada los modos en que la figura del poeta cantor es representada en El gaucho Martín Fierro de José Hernández (publicado en 1872) y El guacho Martín Fierro de Oscar Fariña (2011). Prestamos especial atención al modo en que se formula e intenta contestar la pregunta acerca de quién puede hablar desde la posición del cantor, es decir, desde un saber autorizado por la experiencia y especializado técnica y estéticamente. De este modo, exploramos las maneras en que en ambos textos se producen relaciones complejas con la otredad que permiten un productivo uso del lenguaje.

Palabras claves

autorrepresentación del escritor, literatura argentina reciente, gauchesca.

\begin{abstract}
This article seeks to relieve and to comparatively analyze the ways in which the figure of the singer poet is represented in El gaucho Martín Fierro of José Hernández (published in 1872) and El guacho Martín Fierro of Oscar Farina (2011). We pay special attention to the manner in which it is formulated and tries to answer the question about who can speak from the position of the singer, from an authorized knowledge by the experience, technically and aesthetically skilled. In this way, we explore the ways that both texts produce complex relationships with the otherness that allow a productive use of the language.
\end{abstract}

Keywords

self-representation of the writer, recent Argentine literature, gauchesca. 
saber cómo habla un personaje es saber quién es, [...] descubrir una entonación, una voz, una sintaxis peculiar, es haber descubierto un destino. J.L. Borges El "Martín Fierro", 1953.

Si al leer un texto nos preguntamos ¿quién habla? ¿Cómo son usados los cuerpos y las voces de los sujetos del texto? ¿Cuáles son las relaciones que se establecen entre aquellos que hablan y aquellos que el texto representa?, pensando estas cuestiones siempre podemos llegar a la pregunta por la función de los textos: ¿de qué modo y para qué un texto funciona en un momento histórico determinado? En el caso de El guacho Martín Fierro (Fariña 2011) las preguntas tienen una vuelta más de tuerca, ya que al tratarse de una reescritura de un clásico nacional lo que nos interpela es a saber ¿quién vuelve a hablar con ese tono? ¿La representación de los sujetos es la misma que 140 años antes? Y entonces, llegar también a la pregunta por el funcionamiento del texto en este momento histórico.

Es en este sentido que la pregunta por el rol de la literatura debe ser explorada teniendo en cuenta que en El gaucho Martín Fierro (Hernández 2009) un letrado representa la voz de un gaucho y en este juego de utilización y entrega construye un texto que por sus acciones y sus procedimientos de composición es radicalmente antimilitarista, anarquista y disruptivo del orden social en el cual es gestado (Ludmer). El texto representa el modo en que los cuerpos de los gauchos son usados y abusados por las relaciones de poder en las cuales entran; sin embargo, el texto mismo contiene la paradoja de repetir el gesto: hacia el final, la voz construida del gaucho es acallada violentamente e irrumpe la voz de un narrador en tercera persona del singular representativo del letrado autor del texto. El gaucho Martín Fierro (Hernández) funcionó en el momento de su circulación y consumo como una protesta, una representación de la situación a la que un amplio grupo social era sometido y una forma de intervención desde el campo cultural en la escena política a favor de intereses económicos específicos. 
CATEDRAL TOMADA: Revista de crítica literaria latinoamericana / Journal of Latin American Literary Criticism

Ponerse a cantar. Modos de autorrepresentación del poeta cantor en El gaucho Martín Fierro y en El guacho Martín Fierro.

Por su parte, podemos decir que El guacho Martín Fierro (Fariña) como material cultural va a responder a las preguntas que nos hacemos como lectores críticos desde otro lugar debido a su momento y su modo de composición, esta experiencia literaria va a ser distinta en tanto la relación entre autorrepresentación del escritor y rol de la literatura es diferente. Aquél que habla en este caso también es un letrado pero no un letrado consagrado sino un joven escritor, que publica en una editorial pequeña y nueva. Esto marca las condiciones de circulación del texto que son restringidas al campo especializado: son los circuitos y entramados institucionales -pero también interpersonales- entre la universidad, las librerías y editoriales independientes (por fuera de los conglomerados editoriales transnacionales) y las publicaciones especializadas tanto de papel como digitales. A partir de estas relaciones institucionales e interpersonales se produce información que circula por las redes sociales y las distintas plataformas en línea desde las cuales se difunden tanto actividades (como lecturas de narrativa, mesas redondas de crítica o presentaciones de publicaciones) como los textos mismos.

Las acciones que se representan y los modos de composición textual de $E l$ guacho Martín Fierro (Fariña) hacen que la representación de los sujetos marginales sea estructuralmente análoga a su antecedente (se narran las desgracias de un joven marginal, la violenta opresión del orden social y se despliega generosamente el uso del lenguaje del grupo social representado) pero, habiendo pasado un siglo y medio, el funcionamiento del texto es necesariamente diferente al de su antecedente: el rol social de la literatura en las últimas décadas ha cambiado radicalmente siendo ahora en general una práctica minoritaria, especializada y muchas veces autorreferente y esto impacta y dialoga con las formas de autorrepresentación de los escritores ya que se producen específicas formas de valor. La intervención en la escena política desde el campo de la

${ }^{1}$ La solapa del libro proporciona esta información: "Oscar Fariña nació en Asunción en 1980. Reside en Buenos Aires. Estudió Ciencias de la Comunicación y Letras en la UBA", la editorial que lo distribuye tiene seis libros editados y este título se consigue en una sola librería de la ciudad de Buenos Aires. 
cultura ya sea bajo la forma de la denuncia, el alegato o la propaganda fue una práctica relevante y extendida en el siglo XIX, pero no es la misma la posición de la literatura en el orden social hoy; en este sentido los diferentes roles históricos de la literatura producen distintas formas de construcción de la figura del escritor. De este modo, el rol del texto en las primeras décadas del siglo XXI va a ser fundamentalmente la explotación de recursos de escritura (la reescritura, la intertextualidad, la intervención de un género canónico, en suma: la parodia) como un modo de inscripción e intervención en el medio literario, en el canon y en la tradición.

El punto en el cual se apoya la articulación entre el texto de 2011 con el texto de 1872 es la construcción de la voz que habla como autorrepresentación del poeta cantor. Éste es construido en ambos textos con especificaciones, justificaciones y explicaciones. La autorrepresentación del escritor fue un tópico del romanticismo europeo del siglo XIX tomado y retomado por la tradición literaria argentina y que hoy en día, tanto tiempo después, continúa siendo central en la narrativa reciente. Podemos ver cómo la figura del poeta cantor se autolegitima en relación con el poder de decir, con un uso específico del lenguaje -que es el inspirado- y, de esta manera, tiene la capacidad de constituir una verdad que puede ser comunicada con autoridad ética y estética.

Como decíamos más arriba, la forma de composición textual de ambos textos es divergente: mientras que Hernández es un intelectual formado que utiliza materiales de la cultura popular; Fariña es un joven escritor (nacido en 1980) con una formación incipiente (al momento de publicación del libro no tiene finalizada una carrera universitaria ni otra forma de ejercicio profesional acreditado y el circuito de publicación de sus textos es alternativo al de las grandes editoriales) que utiliza su propia experiencia de vida y el conocimiento lingüístico que ésta le da. El autor ha declarado en una entrevista en una revista digital de cultura: 
No sé si tiene algo estrictamente autobiográfico. Lo que sí me parece es que tengo un manejo del discurso y del código callejero suburbano. Mis tíos viven en el barrio 9 de abril todavía y es un barrio de calle de tierra, en dónde hay rock and roll. Hay agite, hay unos códigos que se manejan de estar ahí y hay como un espíritu de barrio que lo manejo por haber participado, sobre todo en esos años acaso fundamentales, formadores de la adolescencia. Ahora hace mucho que no voy. Las vivencias y las cosas que te marcan te dan ganas de contarlas después. La literatura es eso, contar lo que te marca absolutamente tergiversado. Yo no hago crónica, tampoco denuncia social, entiendo que son lecturas que se desprenden, sobre todo de "El Martín Fierro". En un primer momento estoy haciendo un trabajo verbal, una intervención de discurso. ${ }^{2}$

La experiencia vital a la que alude Fariña es la de los barrios populares del cordón urbano alrededor de la ciudad de Buenos Aires. Generalmente se utiliza la palabra "barrio" para referirse incluso a los asentamientos de emergencia, por eso la mención de la "calle de tierra", es decir, a la precariedad o falta de urbanización. La familia del autor es inmigrante paraguaya, grupo social que sufre generalmente discriminación y marginalidad y que tiene la peculiaridad (sobre otros grupos de inmigrantes de países limítrofes) de hablar una lengua propia (el guaraní). Cuando Fariña dice que "hay rock and roll, hay agite, hay códigos, hay espíritu de barrio" manifiesta con el uso del lenguaje propio de los jóvenes de sectores populares que la convivencia barrial es conflictiva ("hay rock and roll,

\footnotetext{
2 Entrevista en la Revista La voz joven disponible en http://www.lavozjoven.com.ar/?q=contenido/entrevista-oscar-fari\%C3\%B1 1/3/2012. Es ésta una publicación digital que comenzó a aparecer en noviembre de 2011 y que se presenta como "un espacio de publicación y reflexión para jóvenes escritores, artistas, críticos y periodistas" (http://www.lavozjoven.com.ar/?q=pagina/revista-la-voz-joven ). Es un claro exponente del circuito de producción, circulación y consumo de la literatura nueva, escrita por jóvenes, editada y publicada por fuera de las editoriales consagradas y/o comerciales y distribuida, publicitada y abordada críticamente en distintas plataformas en línea (revistas digitales, blogs de escritores y críticos, redes sociales, páginas webs).
} 
hay agite") pero que también ha participado de una legalidad paralela y una solidaridad propia de esa forma de sociabilidad (los "códigos", el "espíritu de barrio"). Inmediatamente después de haber dejado claramente manifestado su participación personal y directa en esta experiencia, indica el proceso de transformación de la vivencia en el proceso de escritura, es decir, el autor en la entrevista explícitamente señala que la autorrepresentación del escritor es un proceso de construcción verbal, ético pero fundamentalmente estético: “contar lo que te marca absolutamente tergiversado, una trabajo verbal, una intervención de discurso". Y refuerza este argumento diferenciando su trabajo de escritura ficcional del de otros géneros como los de la crónica o la denuncia social (non fiction).

En este sentido es que las intenciones declaradas de José Hernández y de Oscar Fariña son divergentes: mientras que el primero, como decíamos, escribe como una denuncia social y con el fin de intervenir en la escena política de su época, el segundo busca intervenir en la escena literaria actual: explícitamente enuncia su intención de dialogar con la tradición literaria argentina, de modificarla, de entrar en relación con ella.

Una continuidad que podemos ver repetirse y perpetuarse entre ambos Martín Fierros es el de la apropiación de las voces ajenas: en un primer movimiento El gaucho Martín Fierro (Hernández) se ha apropiado de las voces de la cultura popular y del folklore, pero en un segundo momento -además de la análoga apropiación de las voces de los sujetos representados en la ficción- El guacho Martín Fierro (Fariña) se apropia de las voces de Hernández. La utilización de las voces ajenas en el caso del texto de 2011 es doble: por un lado, se representan los usos verbales de los sectores populares; pero, por el otro lado, se utiliza la trama y la disposición formal del texto de 1872. De esta manera el texto de Oscar Fariña realiza una doble violencia verbal: hacia la tradición y hacia los sujetos representados y actualiza el gesto de José Hernández pero haciéndolo gesto literario. La intervención es en el campo de la cultura: tanto en el campo 
CATEDRAL TOMADA: Revista de crítica literaria latinoamericana / Journal of Latin American Literary Criticism

Ponerse a cantar. Modos de autorrepresentación del poeta cantor en El gaucho Martín Fierro y en El guacho Martín Fierro.

literario como en el educativo (dado que su antecedente es el clásico literario nacional, el ámbito de la educación formal está necesariamente implicado).

\section{Tanto El gaucho Martín Fierro (Hernández) como El guacho Martín} Fierro (Fariña) tienen la fuerza dramática de un panfleto, un marcado uso de la violencia en el lenguaje popular y la construcción de la figura del poeta cantor como autoridad que dice porque sabe y que sabe porque, aunque no pertenece plenamente al grupo social representado, ha tenido contacto sostenido con su cultura (en el caso de Hernández su material es el folklore, mientras que en el caso de Fariña es su uso de la lengua).

Los dos textos tienen protocolos de lectura claros: el de Hernández tiene un prólogo ("Carta a Don José Zoilo Miguens”) y el de Fariña una contratapa elocuente que con un uso del lenguaje violento (epítetos despectivos, uso de lunfardo o formas verbales propias de jóvenes de sectores populares, provocaciones o formas retóricas de la polémica) expone explícitamente el programa del libro. En ambos casos se sientan las bases de la inteligibilidad de los textos.

En el prólogo de José Hernández se mencionan los “abusos y desgracias de que es víctima esa clase desheredada", se dice que es "un pobre gaucho con todas las imperfecciones de forma que el arte tiene todavía entre ellos y con toda la falta de enlace en sus ideas" y que sus defectos "se encuentran allí como copia o imitación de lo que son realmente.” (Hernández 13)

De este modo, se señala la ajenidad ante el gaucho (hay un "ellos" diferentes al yo de la enunciación y diferente también al interlocutor del prólogo) y la posición ante este otro es de superioridad cultural paternalista. El narrador del prólogo indica que ha construido un

tipo que personificara nuestros gauchos, concentrando el modo de ser, de sentir, de pensar y de expresarse que le es peculiar; dotándolos con todos los fuegos de su imaginación llena de imágenes y coloridos, con todos los 
arranques de su altivez, inmoderados hasta el crimen y con todos los impulsos y arrebatos, hijos de una naturaleza que la educación no ha pulido y suavizado. (Hernández 13)

El objetivo del texto explicitado es

dibujar a grandes rasgos, aunque fielmente, sus costumbres, sus trabajos, sus hábitos de vida, su índole, sus vicios y sus virtudes: ese conjunto que constituye el cuadro de su fisonomía moral, y los accidentes de su existencia. (Hernández 13)

Acorde con esto la representación se propone mimética:

me he esforzar en presentar un tipo[...] cuantos conozcan con propiedad el original, podrán juzgar si hay o no semejanza en la copia[...] en retratar, en fin, lo más fielmente posible que me fuera posible, con todas sus especialidades propias, ese tipo original de nuestras pampas, tan poco conocido por lo mismo que es difícil estudiarlo, tan erróneamente juzgado muchas veces y que al paso que avanzan las conquistas de la civilización va perdiéndose casi por completo. (Hernández 13)

El prólogo plantea entonces la existencia de una realidad social determinada hacia la cual el texto se orienta y sobre la cual se construye como una representación mimética realista para aportar un conocimiento válido.

La utilización del lenguaje popular, tomado de las producciones folklóricas y asimilado en la escritura de este texto, es decir, la utilización de las voces que serán reconocidas por el lector como lenguaje rural, es el recurso privilegiado para la creación de la mímesis, del efecto dramático y del poder de verdad del texto: 
CATEDRAL TOMADA: Revista de crítica literaria latinoamericana / Journal of Latin American Literary Criticism

Ponerse a cantar. Modos de autorrepresentación del poeta cantor en El gaucho Martín Fierro y en El guacho Martín Fierro.

y he deseado todo esto, empeñándome en imitar ese estilo abundante en metáforas, que el gaucho usa sin conocer y sin valorar [...] en copiar sus reflexiones con el sello de la originalidad que las distingue [...] revelándose en ellas esa especie de filosofía propia [...] dibujar el orden de sus impresiones y de sus afectos. (Hernández 14)

Por su parte, el texto de Oscar Fariña tiene, como decíamos, en su contratapa un texto que funciona como protocolo de lectura:

Reducido a instrumento de tortura para bachilleres, souvenir de gringo, o estampita religiosa de sojero exportador, el Martín Fierro se ajusta perfectamente a la definición de clásico que tiraba Borges: aquel libro del que todos hablan y nadie lee.

Ya en esta primera oración Fariña define el estado del texto de Hernández de forma despectiva y apela a Borges como autorización, ya que este gran escritor argentino ha producido fuertes críticas al proceso de canonización del Martín Fierro y ha escrito célebres continuaciones, intervenciones y parodias literarias del mismo. Traer a Borges en esta oportunidad no es un gesto ingenuo, es una clara forma de autorización de Fariña para realizar su cometido. A continuación reseña brevísimamente aquel proceso de canonización y posterior degradación del texto de Hernández: masividad de su recepción, construcción del ser nacional por Leopoldo Lugones, institucionalización académica y utilización de su nombre en la cultura radiotelevisiva (incluyendo así, provocativamente, en la serie de lecturas literarias el hecho de que en Argentina los premios anuales a la programación de radio y televisión se llamen "Premios Martín Fierro").

Así, se trama el protocolo de lectura del libro de Fariña: “¿Cómo hacer para que un libro valioso vuelva a ser leído? La apuesta del presente volumen en 
simple: bardearlo" (2011). Anunciado esto, inmediatamente se alude a otra gran figura de autorización literaria: la poética paródica de Leónidas Lamborghini para enunciar por última vez el modo en que debe leerse El guacho Martín Fierro: "esta reescritura posmovillera del clásico gauchesco intenta devolverle al libro su fuerza original. Dislocarlo apenas para que vuelva a ser el mismo." (Fariña)

Este breve texto en el exterior del libro postula la intención del mismo como una intervención en el campo de la tradición literaria argentina y exhibe rápida pero claramente el conocimiento del derrotero institucional del Martín Fierro y la línea crítica de relectura y reescritura en la cual quiere inscribirse junto con el específico uso del lenguaje que elije practicar Fariña. El objetivo enunciado aquí, entonces, es una intervención en el canon local, una inscripción en este campo como gesto de diálogo con un texto anterior. Como ya mencionamos, el procedimiento verbal por el cual se realiza esta acción es también explícito: la parodia que

funciona como denuncia de su Modelo: en este caso, esa denuncia no guarda ninguna intención reprobativa. Por el contrario, estamos en presencia de una acusación elogiosa, que se pretende homenaje, y va contra toda la lectura coagulada y utilitaria del pasado, de toda clausura del sentido. (Fariña)

Es en este sentido que estos objetivos son explícitos, el registro de esta contratapa ya señala el uso del lenguaje que tiene el libro de Fariña, como se ha señalado: el lenguaje coloquial propio de los sectores populares en general y de los jóvenes de estos sectores en particular es el privilegiado.

Su utilización en un texto que funciona como presentación y protocolo de lectura del libro señala que la relación con este registro es marcadamente diferente

\footnotetext{
3 "Bardear" entre los jóvenes (originalmente entre los jóvenes de sectores populares) significa o bien criticar, agredir o atacar o bien producir algún disturbio o conflicto.
} 
CATEDRAL Tomada: Revista de crítica literaria latinoamericana / Journal of Latin American Literary Criticism

Ponerse a cantar. Modos de autorrepresentación del poeta cantor en El gaucho Martín Fierro y en El guacho Martín Fierro.

a la de Hernández: no se trata aquí de una representación de un grupo ajeno al letrado, sino que es la misma voz del narrador la que elige utilizar este registro. Por eso, seguramente, también lo hace el narrador en tercera persona del singular que cierra el texto cuando Martín Fierro rompe el instrumento musical y termina su payada:

Y le doy fin a mi cumbia / Más que cumbia un re cumbión; / [...] y ya con estos detalles / la secuencia terminé; / por ser posta las canté, / todas las desgracias dichas: / es un tren de altas desdichas / todos los guachos que ven. / Pero pongan su esperanza / en el D10s que los parió; / y acá me despido yo, / que corte batí a mi modo / BARDOS QUE CONOCEN TODOS / PERO QUE NADIE CANTÓ. (Fariña 190, énfasis en el original)

Esta diferencia, entonces, -el narrador del prólogo y del final de Hernández utiliza un registro que no es el del gaucho, mientras que el narrador de Fariña utiliza el mismo registro que sus personajes- es una de las marcas diferenciales de ambos textos.

Para pensar los modos de autorrepresentación del poeta cantor, el análisis de Noé Jitrik del Martín Fierro (1980) que analiza la escena de la payada y la constitución recíproca del canto y el cantor nos puede dar una pauta de la estructura que propone Hernández y es reutilizada por Fariña. Según la lectura de Jitrik el texto se inicia con una acción (cantar), con una motivación (dar cuenta de una experiencia de vida) y un núcleo afectivo (que determina el proceso). Este proceso tiene etapas como la producción con naturalidad, primero; la invocación, después; la acentuación de lo personal, la revisitación de la experiencia del pasado y la conciencia estética del presente del canto. El canto se presenta como una verdad universal aprehensible por todos los hombres, pero también con voluntarismo en el trabajo que se hace al cantar y como un destino personal del cantor elegido. Este destino se asume con orgullo como adquisición de una 
conciencia y una trascendencia y hace que el cantor, si bien pertenece al mundo sobre el cual canta, se destaque en él gracias a su función y a la afirmación que produce sobre ese mundo; es en este sentido que el canto y el cantor se implican y delinean mutuamente en el momento de ponerse a cantar.

Tanto en Hernández como en Fariña todos estos elementos dados desde el comienzo del texto posibilitarán llegar a la conclusión de que la capacidad del canto distingue al cantor del resto del mundo representado: "y aunque [Dios] a las aves les dio / con otras cosas que inoro / esos piquitos como oro / y un plumaje como tabla, / le dio al hombre más tesoro / al darle una lengua que habla" (Hernández 2009: 94); mientras que en Fariña se dirá: “y aunque [el Barba] a las aves les dio / entre otras cosas que inoro, / corte esos picos de loro / y esos plumajes de chanta, / le dio al negro más tesoro / con esa lengua que canta." (183)

El canto es espontáneo e inspirado (no procede del virtuosismo técnico ni del ejercicio intelectual), afrontarlo supone un riesgo vital (aquí es donde vemos las especificidades de estas figuras de poeta cantor que representan las experiencias de puesta en peligro de la vida misma), implica una verdad que se presenta personal pero universal (aquí es donde vemos que el sujeto representado es un sujeto colectivo, ya que el canto no es la expresión de una subjetividad, como en un paradigma romántico, sino la manifestación de la voz de un colectivo que sostiene, justifica y valida al poeta cantor con su experiencia) y que se asume orgullosamente (aquí es donde vemos el núcleo del proceso de autovalidación, autojustificación y autorización del poeta cantor, que sí es un tópico romántico reelaborado). Tanto en El gaucho Martín Fierro (2009) como en El guacho Martín Fierro (2011), canto y cantor representan al mundo del que hablan y al cual pertenecen y la acción de cantar las experiencias pasadas conlleva un peligro ya que ambos cantores van a dar cuenta de la verdad de sujetos en marcado conflicto con la ley.

El texto de José Hernández presenta en su comienzo la escena del canto (“Aquí me pongo a cantar / Al compás de la vigüela”), la motivación (“que el hombre que lo desvela / una pena estrordinaria, / como la ave solitaria / con el 
CATEDRAL TOMADA: Revista de crítica literaria latinoamericana / Journal of Latin American Literary Criticism

Ponerse a cantar. Modos de autorrepresentación del poeta cantor en El gaucho Martín Fierro y en El guacho Martín Fierro.

cantar se consuela.") y la invocación a la ayuda trascendental ("Pido a los santos del cielo / que ayuden mi pensamiento: / les pido en este momento / que voy a cantar mi historia / me refresquen la memoria / y aclaren mi entendimiento. / Vengan santos milagrosos, / vengan todos en mi ayuda / que la lengua se me añuda / y se me turba la vista; / pido a mi Dios que me asista / en una ocasión tan ruda.” (Hernández 15)

Por su parte, el texto de Fariña presenta puntos en común pero algunas modificaciones: “Acá me pongo a cantar / Al compás de la villera, / Que el guacho que lo desvela / Una pena estrordinaria / Cual camuca solitaria / Con la kumbia se consuela.”(9) La escena de canto es similar (se alude a la música popular y la comparación es con un elemento urbano y no rural) pero la invocación ya no es solamente a una instancia trascendental sino también al uso de drogas ilegales:

Pido a los porros del Chelo / Que ayuden mi pensamiento / Les pido en este momento / Que voy a cantar mi historia / Que deliren la memoria / Que esta va con sentimiento. / Vengan porros milagrosos, / Vengan todos en mi ayuda, / Que la lengua se me anuda / Y se me nubla la vista; / Pido a mi D10s que me asista / En esta ocasión conchuda. (Fariña 9)

La alusión al uso de drogas es permanente durante todo el texto y el alto grado de procacidad en el uso del lenguaje refuerza la violencia descripta por la violencia verbal con la cual se la describe, todo lo cual construye el dramatismo del texto e interpela potentemente al lector contemporáneo. El glosario adjunto al final del libro es necesario incluso para un lector con cierto entrenamiento ya que Fariña no se restringe en su construcción verbal al uso de algunas piezas léxicas específicas reconocibles por la comunidad lingüística en general y adjudicables al grupo social representado. 
En ambos textos se alude a la dificultad y el riesgo de contar esta experiencia personal y con la alusión al peligro de esta verdad se refuerza la autoridad del poeta cantor que es una figura específica dentro del mundo representado:

Yo he visto muchos cantores, / con famas bien otenidas / y que despues de alquiridas / no las quieren sustentar: / parece que sin largar se cansaron en partidas. / Mas ande otro criollo pasa / Martin Fierro ha de pasar; / nada lo hace recular / ni las fantasmas lo espantan, / y dende que todos cantan / yo tambien quiero cantar. / Cantando me he de morir, / cantando me han de enterrar / y cantando he de llegar / al pie del eterno Padre; / dende el vientre de mi madre / vine a este mundo a cantar. / Que no se trabe mi lengua / ni me falte la palabra; / el cantar mi gloria labra / y, poniéndomé a cantar, / cantando me han de encontrar / aunque la tierra se abra. (Hernández 16)

Aquí vemos el eje de la especificación del poeta alrededor de la acción de cantar; el texto de 2011 va a respetar esto pero con un corrimiento hacia la acción de robar en el medio de los versos análogos:

Yo vi banda de chabones, / Con famas bien obtenidas, / Y que despué de alquiridas / No las quieren sustentar: / Parece que sin bombear / Ya se van en la lamida. / Ma donde otro guacho pasa / El tincho Fierro va a pasar; / Nada lo hace recular / Ni el grupo GEOF lo espanta, / Y ya que todos son chanta / Yo también quiero afanar. / Choreando voy a morir, / Choreando me han de enterrar, / Y choreando vuá a llegar / Al pie del Eterno Padre: / De la concha de mi madre / Vine a este mundo a chorear. / Que no se trabe mi lengua / Con la merca de los trava; / La cumbia mi gloria labra / Y, 
CATEDRAL TomAdA: Revista de crítica literaria latinoamericana / Journal of Latin American Literary Criticism

Ponerse a cantar. Modos de autorrepresentación del poeta cantor en El gaucho Martín Fierro y en El guacho Martín Fierro.

poniéndome a cantar, / Flashando me han de encontrar / Aunque la tuca se me abra. (Fariña 10)

Esto refuerza la idea de un cantor personalmente comprometido con las acciones de las que habla, su vínculo con el delito es fuerte, explícito y central en su relato y el dramatismo de las acciones es reforzado haciendo que el riesgo vital que implica contar se actualice verso a verso.

Ambos poetas cantores continúan especificándose:

Me siento en un bar del Bajo / Y mi pedo va en aumento; / como si erutara el viento / Hago tiritar los vasos. / Con pelpas, trolas y fasos / Queda aquí mi pensamiento. / Yo no soy cheto estudiado, / Ma si me pongo a rimar / No tengo cuándo acabar / Y me hago viejo cantando / Las cumbias me van brotando / Como el meo al escabiar. (Fariña 11)

Donde en Hernández fue:

Me siento en el plan de un bajo / a cantar un argumento; / como si soplara el viento / hago tiritar los pastos. / Con oros, copas y bastos / juega alli mi pensamiento. / Yo no soy cantor letrao / mas si me pongo a cantar / no tengo cuándo acabar / y me envejezco cantando: / las coplas me van brotando / como agua de manantial. (16)

En ambos casos se especifica el lugar en el cual sucede la acción de cantar (con lugares y sujetos típicamente pertenecientes a la cultura popular) y se señala la naturalidad con la cual se hace esto debido a que es una actividad espontánea y no fruto de la educación, entrenamiento artístico o instrucción. 
Como decíamos más arriba, la autovalidación como poeta cantor que se sustenta en la inspiración conduce y se retroalimenta con la representación de la acciones violentas o propias de una ilegalidad:

Con la guitarra en la mano / ni las moscas se me arriman; / naides me pone el pie encima, /y, cuando el pecho se entona, / hago gemir a la prima / y llorar a la bordona. / Yo soy toro en mi rodeo / y torazo en rodeo ajeno; / siempre me tuve por güeno / y si me quieren probar, / salgan otros a cantar / y veremos quién es menos / No me hago al lao de la güeya / aunque vengan degollando; / con los blandos yo soy blando / y soy duro con los duros, / y ninguno en un apuro / me ha visto andar titubiando. / En el peligro ¡qué Cristos! / el corazón se me enancha, / pues toda la tierra es cancha, / y de eso naides se asombre; / el que se tiene por hombre / ande quiera hace pata ancha. (Hernández 17)

La capacidad de cantar las acciones vividas y justificarlas entra estrechamente en relación con el conjunto de las acciones vitales de los poetas cantores que son enfrentamientos con la ley y/o establecimientos de leyes paralelas. Es en este sentido que al cantar las experiencias del pasado se formulan las preguntas por quién es delincuente y por cuál es la ley, pero estas preguntas se dan en relación con la acción de cantar. Esto en Fariña se presenta del mismo modo: se comienza aludiendo a la valentía que inspira el canto para luego contar los enfrentamientos con la ley:

Con el pianito en la mano / Ni la yuta se me arrima; / nadie me pone el pie encima, / y cuando el visio me entona, / Hago gemir a mi prima / Que se copa de putona. / Yo soy chorro en mi barrio / Y chorrazo en barrio ajeno; / Siempre me tuve por güeno / Y si me quieren probar / Salgan otros a afanar / Y veremo quién es meno. / Nunca escondo la cabeza / Aunque 
CATEDRAL Tomada: Revista de crítica literaria latinoamericana / Journal of Latin American Literary Criticism

Ponerse a cantar. Modos de autorrepresentación del poeta cantor en El gaucho Martín Fierro y en El guacho Martín Fierro.

vengan patrullando; / A los blandos me los mando / Y soy duro con los duros, / Y ninguno en un apuro / Me ha visto andar arrugando. / En el peligro ¡qué mierda! / La poronga se me ensancha / Soy local en toda cancha, / Y de esto nadie se asombre: / El que se tiene por hombre / A cualquiera se lo garcha. (12)

A su vez, el enfrentamiento con la ley penal tiene su correlato en el canto con el enfrentamiento con la legalidad verbal, con el canon lingüístico y literario mediante el cual el cantor se autorrepresenta y autovalidad más fuertemente:

Soy guacho, y entiendalón / Como mi lengua lo esplica: / Para mí tu verga es chica / Y tu hermana es ya mayor; / Chamuyan los que se pican / Que así se viaja mejor. / Nací como nace el pedo / En el fondo de algún bar / Nadie me puede afanar / Eso que Barba me dio: / Lo que al barrio traje yo / Del barrio voy a llevar. (Fariña 13)

Y:

Soy gaucho, y entiéndaló / como mi lengua lo esplica: / para mi la tierra es chica / y pudiera ser mayor; / ni la víbora me pica / ni quema mi frente el sol. / Nací como nace el peje / en el fondo de la mar; naides me puede quitar / aquello que Dios me dio: / lo que al mundo truje yo / del mundo lo he de llevar. (18)

Nuevamente el movimiento es de retroalimentación entre la acción de cantar y las experiencias vitales, el uso de la lengua está justificado por las acciones realizadas y haber experimentado el peligro constituye el poder de verdad del canto construido. 
El canto de la experiencia en la lengua del poeta cantor hace justicia a su vida y a su mundo tanto en 1872 como en 2011 con versos casi idénticos:

Y sepan cuantos escuchan / de mis penas el relato / que nunca péleo ni mato / sino por necesidá / y que a tanta alversidá / sólo me arrojó el mal trato. / Y atiendan la relación / que hace un gaucho perseguido, / que padre y marido ha sido / empeñoso y diligente, / y sin embargo la gente / lo tiene por un bandido (Hernández 19)

$\mathrm{y}$

Y sepan cuantos escuchan / de mis penas el relato / que nunca péleo ni mato / sino por necesidá / y que a tanta alversidá / sólo me arrojó el mal trato. / Y calen esta cansión / Que hace un guacho perseguido, / Que padre y marido ha sido, / Un poquito delincuente, / Y sin embargo la gente / Lo tiene por un bandido. (Fariña 16).

La autorrepresentación del escritor y de la escritura es una de las formas más proliferantes en la literatura argentina reciente (desde la transición a la democracia en 1983 luego de la Dictadura cívico militar de 1976-1983 pero, fundamentalmente, en la última década, luego de la crisis cultural y política de la hegemonía neoliberal de 2001-2002). En el caso del texto de Oscar Fariña encontramos juntos dos gestos ampliamente explotados en el campo literario actual: por un lado, escribir con materiales literarios (el título, la estructura, la trama, las acciones son tomados del canon, del Martín Fierro) y, por el otro, trabajar complejamente en el nivel verbal (se trabaja con el lenguaje usando el registro del grupo social que se quiere representar).

En miras a pensar los vínculos que se producen y reproducen entre la autorrepresentación del poeta cantor y el rol que la literatura se propone ejercer o 
los modos en que la construcción de la figura del autor permiten pensar las experiencias de la literatura, es importante señalar las especificidades históricas del texto de 2011. Si, como decíamos antes, en El gaucho Martín Fierro (Hernández) se discute siempre el estatuto de la legalidad y la relación entre los ilegalismos y los desposeídos, es decir, se busca contestar siempre a la pregunta por quién es delincuente, creemos que además de esta pregunta-que también obviamente articula a El guacho Martín Fierro (Fariña) por ser estructuralmente análogo a su antecedente- en ambos textos se contesta a la pregunta por quién puede hablar desde la posición del cantor, es decir, desde un saber autorizado por la experiencia de aquel que escribe y especializado técnica y estéticamente. Aquí es donde la relación con la otredad es más compleja: en ambos casos el escritor es exterior al grupo representado por poseer la técnica, pero, de algún modo, interior al mismo por poseer la experiencia. La exterioridad o interioridad en ambos casos se da mediada por el folklore, en el caso de Hernández, y por el uso del lenguaje coloquial de un grupo social, en el caso de Fariña; pero lo que da a los dos textos la potencia como escena verbal es que al no ser construidos desde la otredad radical no generan una división dicotómica moral (del tipo "buenos/malos") sino que permiten la emergencia y el desarrollo de personajes y situaciones complejas y ambivalentes moralmente.

Como decíamos más arriba, el uso del lenguaje en Fariña es rico y potente porque exhibe un conocimiento del mismo que hace justicia a la complejidad verbal. El guacho Martín Fierro (Fariña) no sólo es un texto que respeta la versificación de su antecedente y que está rimado, sino que, además, utiliza una enorme cantidad de piezas léxicas propias del registro del grupo social representado que hacen indispensable el glosario, interviene la sintaxis cuando es necesario e, incluso, en la disposición tipográfica con la inclusión de gráficos y de alteraciones ortográficas. Esta literatura, así, ofrece un espacio de significación compleja que no abunda en el orden social actual. Es claro que los materiales con los que el texto trabaja no son las representaciones de los medios masivos de comunicación (tanto la música como la ficción televisiva) que construyen 
estereotipos de grupos sociales desposeídos o marginales a partir del uso de solamente una pequeña cantidad de piezas léxicas más o menos conocidas por los hablantes locales en general y producen simplificaciones estigmatizantes.

Estas formas de representación al proceder por simplificación producen generalmente el efecto del exotismo o de la estetización. También en otras zonas de la literatura argentina reciente, los grupos sociales desposeídos o marginales, así como, la desigualdad social, son representados como la ajenidad radical que no se conoce y seduce o se teme; es decir, la representación en estos casos procede a una asimilación estetizante ya sea por la belleza, ya sea por el horror.

Por el contrario, la reescritura del Martín Fierro en 2011 produce cambios diestramente en las acciones (las especificaciones de los lugares de residencia y circulación -los barrios urbanos pobres, las instituciones de encarcelamiento-, la identificación de la otredad hacia el interior del grupo representado -la xenofobia y el racismo hacia los inmigrantes de países limítrofes pero también el machismoo la asignación de los roles de los opresores -las fuerzas de seguridad, el servicio penitenciario y el sistema judicial-) que demuestran un conocimiento complejo y profundo de las situaciones representadas y supera los usos propios del exotismo o la estetización que suelen desarrollar los medios masivos de comunicación y reutilizar algunas producciones literarias recientes.

Sumada a la mencionada ambivalencia moral de los protagonistas, otro de los resultados donde esta complejidad puede verse es en la tensión entre lo cómico y lo trágico que aparece en el texto de Fariña, ya que sólo en una construcción que haga justicia a la complejidad del lenguaje y no produzca estereotipos hay lugar para un uso crítico de la risa. Fariña recoge en su texto las problemáticas de la literatura actual (principalmente la formación de una identidad local -la barrial y la carcelaria- pero simultáneamente transnacional -en relación con la inmigración-) a partir de relocalizar el registro, los temas y las posiciones del texto de Hernández en 2011: el uso del lenguaje de un grupo social determinado (los "villeros", "chabones", las "pibas" Fariña 2011: 9-ss), las costumbres y acciones de estos sujetos (el "bardo", el "arruinarse", el "rescate" 
Fariña 20) y las relaciones en las que entran entre ellos y con otros sujetos (la "yuta", los "cobanis", los "ratis", los "pitufos", el "Servicio", los "cachivaches" Fariña 12). Es en este sentido que la reescritura del Martín Fierro toma de su antecedente lo mejor del sentido literario (la posibilidad de la ambivalencia, la complejidad de los personajes, el uso violento del lenguaje para dar cuenta de la violencia de las acciones) y realiza el gesto de la actualización de su forma y de su contenido con habilidad ya que no reduce ni las acciones ni los personajes a representaciones estereotipadas.

El gesto de Fariña se propone desde su texto programático y desde los procedimientos de composición verbal elegidos como una intervención en el medio literario de acuerdo con el rol social -entendido como ese vínculo específico entre la literatura y el orden social, entre los participantes del campo material de la literatura y las instituciones, entre la experiencia de la literatura y la construcción de la subjetividad del escritor- que la práctica literaria tiene de forma predominante recientemente: ser un campo pequeño que produce valor en relación con la especialización, la profesionalización y el mercado editorial.

Si el desafío y el lamento son los tonos de la patria (Ludmer), podemos pensar que también lamento y desafío guían al texto de Fariña; lamento ante el estado del canon y acerca del camino seguido por el Martín Fierro: “perdió el entusiasmo popular con que fue recibido en sus primeros años, y su radio de influencia se confinó al sadismo de ciertas profesoras y la exégesis crítica. Hoy en día sólo se invoca su nombre una vez al año para premiar a los popes de la radiotelevisión local" (Fariña) y desafío al campo literario: hacer que el Martín Fierro vuelva a ser leído (Fariña) con una potencia renovada, más allá de la historia, de los usos y derroteros de la tradición y la cultura nacional. No es un objetivo poco ambicioso. 


\section{Bibliografía}

Fariña, Oscar. El guacho Martín Fierro. Buenos Aires: Factotum Ediciones, 2011.

Hernández, José. Martín Fierro. Buenos Aires: Colihue, 2009.

Jitrik, Noe. "El tema del canto en 'El Martín Fierro"” en Leumann, Borges, Martínez Estrada Martín Fierro y su crítica. Antología. Buenos Aires: CEAL, 1980.

Ludmer, Josefina. El género gauchesco. Un tratado sobre la patria. Buenos Aires: Libros Perfil, 2000.

(c) $\mathbf{E Y}$

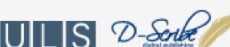

New articles in this journal are licensed under a Creative Commons Attribution 4.0 United States License.

This site is published by the University Library System, University of Pittsburgh as part of its D-Scribe Digital Publishing Program and is cosponsored by the University of Pittsburgh Press. 